\title{
Body Composition, Changing Physiological Functions and Nutrient Requirements of the Elderly
}

\author{
Ibrahim Elmadfa Alexa L. Meyer \\ Department of Nutritional Sciences, University of Vienna, Vienna, Austria
}

\section{Key Words}

Body composition - Nutrient requirements - Physiological

functions $\cdot$ Aging $\cdot$ Elderly

\begin{abstract}
Age has an important impact on body composition. The decreases of lean body mass and total body water accompanied by an increase of body fat are the most relevant changes leading to a reduction of the basal metabolic rate. Due to this and the fact that elderly people are generally less physically active, energy needs are lower. However, the requirements for most micronutrients are not reduced. Indeed, impaired absorption of some vitamins and minerals like cobalamin and calcium can cause deficiencies. An adequate calcium supply is particularly important as with ongoing age, bone mass decreases as well, making elderly prone to osteoporosis. The reduced ability to synthesize vitamin D and the lower sunlight exposure of many elderly further aggravate this issue. There is evidence to consider the supply of some important dietary antioxidants as critical in some elderly, namely vitamin $C$ and $\beta$-carotene as well as zinc. In light of age-related decreases in the activities of antioxidant enzymes, a sufficient supply of dietary antioxidants is important, especially as oxidative damage is thought to contribute to the deteriorating processes associated with aging and promote cardiovascular disease, cognitive disorders, cancer and diabetes mellitus that occur more frequently in older
\end{abstract}

people. The first three are also associated with an insufficiency of folate, another critical nutrient in the elderly. Therefore, dietary guidelines should strive to optimize the immune function and reduce disease risk of the elderly.

Copyright $\odot 2008$ S. Karger AG, Basel

\section{Introduction}

With the increasing life expectancy, the number of elderly people is steadily rising. Despite improvements in medical care prolonging the lifetime in good health, dependency is also increasing with age. Therefore, care should be given to the special nutrition requirements of elderly.

Indeed, the impacts of aging on body composition have an influence on the nutritional needs of a person. For both genders, the part of total body weight that is accounted for by fat increases by about $50 \%$. As adipose tissue has no significant metabolic activity, the basal metabolic rate decreases by about $2 \%$ per decade. Accordingly, oxygen use of the whole body is reduced, but not that of nonmuscular tissues [1]. In addition, elderly are generally less physically active than young persons so that activity energy expenditure is also lower. This can lead to overweight and its prevalence is indeed too high in the younger elderly. Thus, in the Austrian Nutrition Report $2003,25 \%$ of those aged $65-74$ years were considered as

Ibrahim Elmadf

Department of Nutritional Sciences, University of Vienna

Althanstrasse 14

AT-1090 Wien (Austria)

Tel. +43 14277 54911, Fax +43 14277 9549, E-Mail ibrahim.elmadfa@univie.ac.at 
overweight, i.e. having a body mass index (BMI) over 29 in accordance with the definition for older adults. However, with increasing age, the number of overweight persons decreases. Among the over 84 -year-olds, only $11 \%$ fall into this category. At the same time, the prevalence of underweight is rising, reaching as much as $29 \%$ in this age group [2]. In Germany, about $35-56 \%$ of geriatric patients show symptoms of malnutrition and this is an important cause for morbidity and mortality [3].

\section{Critical Nutrients in the Aged}

Malnutrition is not only characterized by insufficient energy intake. Indeed, while the caloric needs are lower in the elderly, the demands for most vitamins, minerals and trace elements are not or only slightly reduced. Protein requirements might even be somewhat higher than for younger adults, as some studies suggest [4]. Only iron needs show a marked decline in women after the menopause but they still remain on the level recommended for men. Thus, foods with a higher nutrient density should be preferred. Impaired absorption of certain micronutrients is commonly observed in elderly. The prevalence of atrophic gastritis increases with age affecting as much as more than $30 \%$ of elderly $[5,6]$. As a consequence, vitamin $B_{12}$ absorption can be significantly lower due to a disturbed secretion of intrinsic factor needed for the stabilization and uptake of the vitamin.

Calcium and vitamin D are two other examples of nutrients whose absorption and status is influenced by age. For both, an age-related decrease of receptor expression in the duodenum was shown in women [7]. Furthermore, the synthesis of vitamin $\mathrm{D}$ in the skin decreases with age [8]. A survey on micronutrient status in Viennese elderly revealed a moderate calcium deficiency in $17 \%$ of the subjects. Vitamin D status was more critical with $22 \%$ of the subjects being moderately and 3\% severely deficient (serum concentrations below 25 and $12 \mathrm{nmol} / \mathrm{l}$, respectively) [9].

This is of importance as bone mass decreases with age especially after the menopause in women, making them prone to osteoporosis [10-12].

\section{Water Household and Kidney Function}

The decline in lean body mass is also characterized by a lower water content of the organism. Previous studies found average losses of about 4 liters of total body water for men and of approximately 6 liters for women from the ages of 20 to 80 years. The percentage of body weight accounted for by water falls from about 60 to about $45 \%$. The hydration of the fat-free mass is, however, not influenced by age $[13,14]$. Fluid metabolism in the elderly is not only characterized by a lower water content of the body but also by reduced kidney function. Renal blood flow decreases as does the glomerular filtration rate. Beginning at the fifth age decade, the weight of the kidneys progressively falls by about $20-30 \%$, the number of intact glomeruli decreases as the number of sclerotic glomeruli rises. The capacity of the kidney to adapt the urine concentration and maintain electrolyte balances appropriately deteriorates. This can result in disturbed osmolarity and dehydration [15]. The problem is further aggravated by the impaired thirst perception that is observed in elderly subjects. Studies that were mainly conducted in rats point to impaired responses to hypertonicity and hypovolemia apparently due to reduced baroreceptor and cardiopulmonary reflexes as the reasons for this phenomenon, while the effects of angiotensin are not different between age groups. Overall, elderly seem able to maintain a balanced fluid intake under normal conditions but have difficulties to adapt to stress situations like heat and water deprivation $[16,17]$.

\section{Perturbed Tasting and Smelling}

Food consumption is frequently altered in aged people due to reduced olfactory and gustatory functions. It was shown that detection and recognition thresholds for all four basic tastes are higher for elderly meaning that they need higher tastant concentrations $[18,19]$. Furthermore, the density of taste buds decreases with age [22]. Alongside with poorer appetite and dysphagia that are also common in aged persons, impaired taste perception reduces the pleasure of eating and thereby can contribute to malnutrition [20].

\section{Effects of Medications}

Appetite can further be affected by various medications. Depending on the drug, it can be increased or diminished. Certain drugs alter the taste of food so that they may be rejected by the users. In addition, drugs can also affect the absorption and metabolism of certain nutrients. This is the case for some of the most frequently prescribed medications, namely laxatives, antibiotics and 
antirheumatics. For example, laxatives accelerate intestinal transit thereby reducing the residence time of food in the gut so that nutrients may not be absorbed efficiently [21]. This is all the more important as many elderly regularly take one or more drugs. A survey in Austrian elderly showed that intake of drugs was related to appetite in a dose-dependent manner. The higher the number of medications taken daily, the more likely was the loss of appetite in the subjects. Appetite was also related to selfperceived health and well-being: elderly feeling healthy also reported good appetite, while more than a third of those perceiving their health as bad had no appetite [2].

\section{Oxidative Stress and Impaired Immune Function}

In addition to the already mentioned critical nutrients, adequate intake of antioxidants is particularly important for elderly subjects. Indeed, one of the leading aging theories ascribes many of the deteriorating effects to the action of oxidative agents. These are free radicals generated in the body during normal physiological processes like respiration, energy metabolism and immune reactions for instance, and the organism has evolved a number of mechanisms and means to scavenge them. However, these become less efficient with ongoing age leaving tissues and cell structures increasingly exposed to oxidative stress [23]. Adequate supply of nonenzymatic antioxidants like $\beta$-carotene, $\alpha$-tocopherol and ascorbic acid can improve the oxidative balance and they do not even have to be given as supplements, but foods rich in these compounds also have shown positive effects $[24,25]$.

Aging also has an influence on immune function. There is a decline of primary and peripheral lymphoid tissues. Thymic atrophy and replacement of hematopoietic bone marrow by adipose tissue are two manifestations of these processes. The numbers of certain cells involved in immune defense, like $\mathrm{T}$ cells for instance, are altered leading to shifts in the distributions of the subpopulations together with functional deficits. Thus, B cells show lower antibody production, while the T cells' cytokine secretion generally declines. The response to vaccination is lower than in younger adults making elderly more vulnerable to infections and tumors [26]. It is well recognized that nutrition has an influence on the immune system. Special focus is on trace elements like selenium, zinc and iron as well as vitamins, especially A, $\mathrm{E}$ and $\mathrm{C}$, and polyunsaturated omega- 3 fatty acids. These nutrients play a role in cell replication as antioxidants protecting the immune cells from the noxious effects of reactive oxygen and nitrogen species that are generated in the fight against pathogens or can even modulate the immunological response. Adequate supply of the essential nutrients can therefore leverage the age-related impairment of the immune function. However, intake through a varied and balanced nutrition seems to have better effects than high-dosage supplements of single nutrients [27].

\section{Deteriorated Micronutrient Status and Increased Disease Risk}

Besides physiological age-related effects, the incidence of pathological changes also increases with the years. Elderly people more frequently suffer from chronic diseases like diabetes mellitus, hyperlipidemia, hypertension and cancer. The prevalence of hyperhomocysteinemia is also higher in this group. High homocysteine concentrations $(>15 \mu \mathrm{mol} / \mathrm{l})$ in the blood are considered a risk factor for cardiovascular disease and are a consequence of deficiencies in vitamins $B_{12}, B_{6}$ as well as folate. Status of these micronutrients is often insufficient in elderly [28, 29]. In the case of vitamin $B_{12}$, this is, as already mentioned, mainly due to an impaired absorption rather than low intake. In a Viennese collective of elderly, plasma concentrations were below the reference level of $200 \mathrm{ng} / \mathrm{l}$ in about $18 \%$ of the subjects, although daily intake was generally well above the $\mathrm{D}-\mathrm{A}-\mathrm{CH}$ recommendation of 3 $\mu \mathrm{g}[2,9]$. In contrast, the low status of folate and vitamin $\mathrm{B}_{6}$ that was observed in 56 and $54 \%$ of the Viennese elderly, respectively, with severe insufficiencies in 20 and $39 \%$ of the survey participants, seems to be mainly caused by low intake that is not only a problem in Austria but affects other European countries alike [30].

\section{Conclusion}

Age-related physiological changes - whether associated with disease or not - have a marked impact not only on health in general but also on nutrient requirements and food preferences in the elderly. Nutrition offers the means to improve health and well-being when chosen carefully. Food-based dietary guidelines for elderly are basically the same as for young adults, propagating a balanced varied nutrition that is rich in complex carbohydrate sources such as whole-grain cereals and products thereof as well as potatoes, vegetables and fruits. Milk products should be included to supply sufficient calcium, 
while fish provides vitamin $\mathrm{D}$ and essential fatty acids. Special importance should be accorded to beverages. While adequate water supply is also important for younger people, it is even more so for the elderly in view of their potentially impaired thirst perception and reduced renal functions. With the increasing demand for readyto-eat meals and food prepared in care institutions, diffusion of reliable guidelines is strongly needed.

\section{Disclosure Statement}

The authors received no funding or financial aids.

\section{References}

1 Tzankoff SP, Norris AH: Longitudinal changes in basal metabolism in man. J Appl Physiol 1978;45:536-539.

2 Elmadfa I, Freisling H, König J, et al: Österreichischer Ernährungsbericht 2003, 1. Aufl., Wien, 2003.

3 Küppers C: Mangelernährung in Deutschland. Ernährungsumschau 2007;54:B25B28.

4 Campbell WW, Crim MC, Dallal GE, Young VR, Evans WJ: Increased protein requirements in elderly people: new data and retrospective reassessments. Am J Clin Nutr 1994; 60:501-509.

$\checkmark 5$ van Asselt DZ, de Groot LC, van Staveren WA, Blom HJ, Wevers RA, Biemond I, Hoefnagels WH: Role of cobalamin intake and atrophic gastritis in mild cobalamin deficiency in older Dutch subjects. Am J Clin Nutr 1998;68:328-334.

6 Tominaga S, Inoue M, Tajima K, Kato I, Kobayashi S: Epidemiology of stomach cancer in Japan - with special reference to the relationship between atrophic gastritis and stomach cancer. Scientific Report of the Aichi Cancer Center Research Institute, 1994-1995.

7 Walters JR, Balesaria S, Chavele KM, Taylor V, Berry JL, Khair U, Barley NF, van Heel DA, Field J, Hayat JO, Bhattacharjee A, Jeffery R, Poulsom R: Calcium channel TRPV6 expression in human duodenum: different relationships to the vitamin D system and aging in men and women. J Bone Miner Res 2006;21:1770-1777.

8 MacLaughlin J, Holick MF: Aging decreases the capacity of human skin to produce vitamin $D_{3}$. J Clin Invest 1985;76:1536-1538.

9 Elmadfa I, Blachfelner J, Freisling H: Zweiter Wiener Ernährungsbericht (2nd Viennese Nutrition Report). Municipality of Vienna, 2004.
0 Saville PD: Changes in bone mass with age and alcoholism. J Bone Joint Surg 1965;47: 492-499.

11 Meema S, Reid DBW, Meema HE: Age trends of bone minerals mass, muscle width, and subcutaneous fat in normals and osteoporotics. Calcif Tissue Res 1973;12:101-112.

12 O'Flaherty EJ: Modeling normal aging bone loss, with consideration of bone loss in osteoporosis. Toxicol Sci 2000;55:171-188.

13 Schoeller DA: Changes in total body water with age. Am J Clin Nutr 1989;50:11761181.

>14 Chumlea WC, Guo SS, Zeller CM, Reo NV, Siervogel RM: Total body water data for white adults 18 to 64 years of age: the Fels Longitudinal Study. Kidney Int 1999;56: 244-252.

15 Silva FG: The aging kidney: a review. Part 1. Int Urol Nephrol 2005;37:185-205.

16 Phillips PA, Bretherton M, Johnston CI, Gray L: Reduced osmotic thirst in healthy elderly men. Am J Physiol Regul Integr Comp Physiol 1991;261:R166-R171.

17 McKinley MJ, Denton DA, Thomas CJ, Woods RL, Mathai ML: Differential effects of aging on fluid intake in response to hypovolemia, hypertonicity, and hormonal stimuli in Munich Wistar rats. Proc Natl Acad Sci USA 2006;103:3450-3455.

18 Fukunaga A, Uematsu H, Sugimoto K: Influences of aging on taste perception and oral somatic sensation. J Gerontol [A] 2005;60: 109-113.

$>19$ Nordin S, Brämerson A, Bringlöv E, Kobal G, Hummel T, Bende M: Substance and tongue-region specific loss in specific tastequality identification in elderly adults. Eur Arch Otorhinolaryngol 2007;264:285-289.

20 Hickson M: Malnutrition and ageing. Postgrad Med J 2006;82:2-8.
21 Hay K, Ledikwe JH, Smiciklas-Wright H, Treu J: Nutrition and aging: drug-nutrient interactions. background reading. University Park, Penn State Distribution Center, 2001.

22 Winkler S, Garg AK, Mekayarajjananonth T, Bakaeen LG, Khan E: Depressed taste and smell in geriatric patients. J Am Dent Assoc 1999;130:1759-1765.

23 Gilca M, Stoian I, Atanasiu V, Virgolici B: The oxidative hypothesis of senescence. J Postgrad Med 2007;53:207-213.

24 Wouters-Wesseling W, Wagenaar LW, de Groot LCPGM, Bindels JG, van Staveren WA: Biochemical antioxidant levels of respond to supplementation with enriched drink in frail elderly people. J Am Coll Nutr 2003;22:232-238.

25 Wagner K-H, Haber P, Elmadfa I: Antioxidant status and fitness in seniors aerobically trained and supplemented with a multivitamin drink. Forum Nutr 2003;56:261-262.

26 Gruver AL, Hudson LL, Sempowski GD: Immunosenescence of ageing. J Pathol 2007; 211:144-156.

27 Chandra RK: Impact of nutritional status and nutrient supplements on immune responses and incidence of infection in older individuals. Ageing Res Rev 2004;3:91-104.

28 Clarke R, Refsum H, Birks J, Evans JG, Johnston C, Sherliker P, Ueland PM, Schneede J, McPartlin J, Nexo E, Scott JM: Screening for vitamin B-12 and folate deficiency in older persons. Am J Clin Nutr 2003;77:12411247.

29 Wolters M, Hermann S, Hahn A: B vitamin status and concentrations of homocysteine and methylmalonic acid in elderly German women. Am J Clin Nutr 2003;78:765-772.

30 Elmadfa I, Weichselbaum E: European $\mathrm{Nu}-$ trition and Health Report 2004. Forum Nutr 2004;58. 